\title{
Borescope inspection of endoscope working channels: Why and how?
}

다 (i)

\author{
Authors \\ Cori L. Ofstead, Krystina M. Hopkins, John E. Eiland \\ Institution \\ Ofstead and Associates, Inc., Saint Paul, Minnesota, United \\ States \\ Bibliography \\ Endosc Int Open 2022; 10: E109-E111 \\ DOI 10.1055/a-1512-2813 \\ ISSN 2364-3722 \\ (C) 2022. The Author(s). \\ This is an open access article published by Thieme under the terms of the Creative \\ Commons Attribution-NonDerivative-NonCommercial License, permitting copying \\ and reproduction so long as the original work is given appropriate credit. Contents \\ may not be used for commercial purposes, or adapted, remixed, transformed or \\ built upon. (https://creativecommons.org/licenses/by-nc-nd/4.0/) \\ Georg Thieme Verlag KG, Rüdigerstraße 14, \\ 70469 Stuttgart, Germany \\ Corresponding author \\ Cori L. Ofstead, Ofstead \& Associates, Inc., 1360 Energy Park \\ Drive, Suite 300, Saint Paul, MN, United States \\ Fax: +651-647-6287 \\ cori@ofsteadinsights.com
}

Borescopes are useful tools for inspecting endoscope channels and interior components, which are otherwise obscured due to being narrow and encased in opaque material. Their use is now recommended in many reprocessing guidelines. Our research team has conducted several studies on endoscope reprocessing effectiveness, during which we performed hundreds of borescope exams on a diverse array of endoscopes, including ureteroscopes, cystoscopes, bronchoscopes, endobronchial ultrasound endoscopes, gastroscopes, colonoscopes, duodenoscopes, and endoscopic ultrasound endoscopes. The interior architecture of various brands and models is diverse, with strikingly different appearance.

Over time, our team and others discovered that nearly $100 \%$ of channels have visible defects, and the need for borescope inspections has become more apparent [1-4]. Myriad defects have been observed in patient-ready endoscopes, including fluid droplets, soil, staining, dents, scratches, shredding, debris, tissue glue, and fragments of accessories ( $>$ Fig. 1).

The clinical implications are sobering. Several peer-reviewed investigations have linked infections and deaths to visibly contaminated or damaged endoscopes ( $\triangleright$ Table 1 ) [5-7]. In one outbreak, two multidrug-resistant pathogens harbored inside a bronchoscope infected 19 patients before a borescope examination detected "proteinaceous debris" and a channel defect [5]. The authors hypothesized that retained debris "may have contributed to the establishment of a biofilm and subsequent contamination" and concluded that borescope examination is a "critical component of device reprocessing" [5]. Numerous adverse events linked to inadequately reprocessed endoscopes have been reported to the US Food and Drug Administration $(\triangleright$ Table 1$)$. These reports described retained tissue, stents, balloons, and reprocessing brush tips, which were discovered when they were expelled into another patient during a subsequent procedure.

Given our experience with borescope exams, we read with interest the new study by Barakat et al. on the use of artificial intelligence $(\mathrm{Al})$ to assist with borescope examinations. We agree that human factors, including training, subjectivity, and the time and expertise needed to conduct borescope exams, can be barriers to implementation. We commend the authors for exploring how Al-supported borescope examinations could overcome these barriers. As Barakat et al. emphasized, endoscopes can be damaged during routine procedures, reprocessing, or transport, and as such, frequent borescope examinations would be beneficial. We have observed two approaches to implementing borescope inspections, namely using them for quality assurance during every reprocessing cycle or for periodic assessment of the endoscope fleet. Both approaches require careful consideration of program goals and logistics, such as what borescope sizes are needed; where, when and by whom exams will be performed; how exams fit into the reprocessing workflow; what will be done when defects are observed; and how to ensure that borescopes do not contribute to cross-contamination among the endoscope fleet or borescopist exposure to pathogens.

The value of inspections is dependent on image quality, which is impacted by the skill and technique used by the borescopist as well as the size and characteristics of the endoscope and whether soil, debris, fluid, lubricants, or simethicone are present and stick to the lens during the exam. The interpretation of observations by human borescopists or Al systems depends on their experience with diverse internal architecture of 


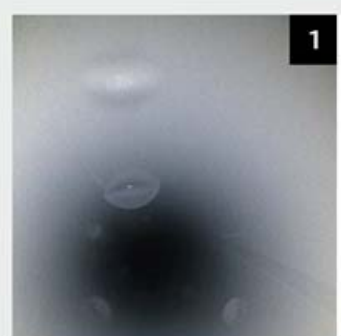

Droplets

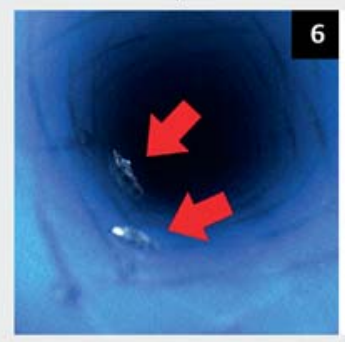

Manufacturing debris

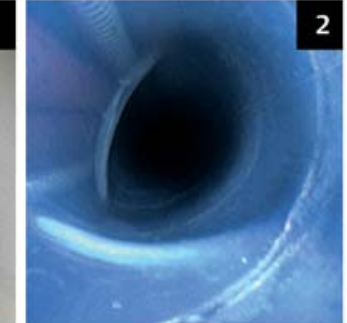

Dents in channel

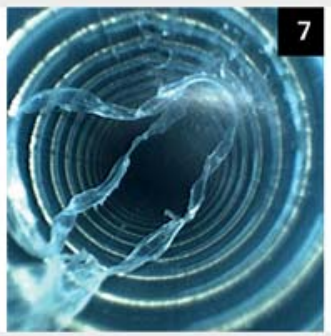

Filamentous debris

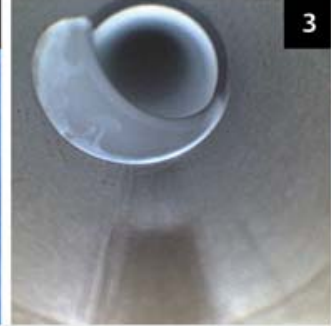

Simethicone

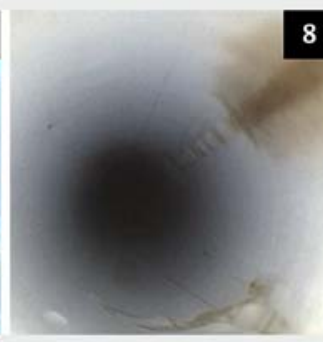

Scratching and staining

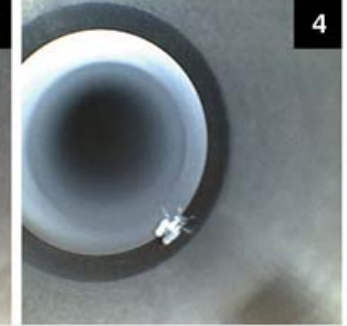

Hinge of hemostasis clip

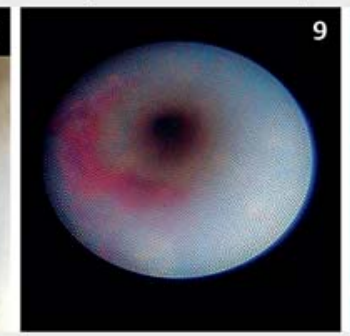

Manufacturer marking

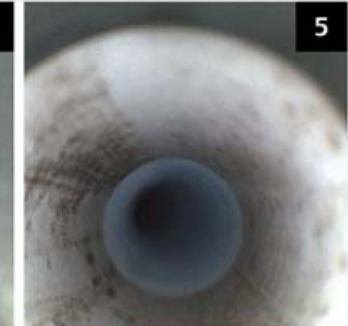

Soil in channel

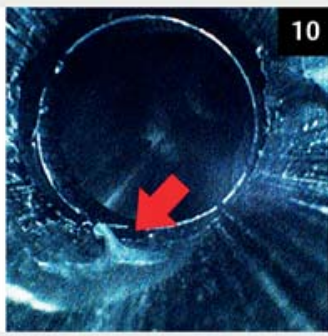

Tissue glue

- Fig. 1 Diverse defects and retained debris in endoscope channels. Source: Ofstead \& Associates, Inc.

- Table 1 Patient exposure to endoscopes with damage or retained debris and contamination (2018-2020).

\begin{tabular}{|c|c|c|}
\hline Endoscope type & Defects or retained material & Debris discovery and outcomes \\
\hline \multicolumn{3}{|l|}{ Infections } \\
\hline Bronchoscope [5] & $\begin{array}{l}\text { Channel defects } \\
\text { Proteinaceous debris }\end{array}$ & 19 patients infected with superbugs; 10 died \\
\hline Duodenoscope [6] & $\begin{array}{l}\text { Cracked biopsy channel } \\
\text { Brown staining around elevator }\end{array}$ & 27 patients infected with superbug \\
\hline Ureteroscope [7] & $\begin{array}{l}\text { Surface cuts } \\
\text { Non-intact channel lining }\end{array}$ & 13 patients infected with superbug; 8 developed sepsis \\
\hline \multicolumn{3}{|c|}{ Exposure to tissue retained in channels } \\
\hline Bronchoscope [8] & Mesh or tissue & Pushed from channel into another patient's lung \\
\hline Colonoscope [9] & Polyp & Pushed from channel into another patient \\
\hline Gastroscope [10] & Foreign tissue & Pushed from channel into another patient \\
\hline \multicolumn{3}{|c|}{ Exposure to retained devices } \\
\hline Colonoscope [11] & Clip & Fell into another patient \\
\hline Duodenoscope [12] & Pancreatic stent & Found in channel after several weeks; retrieved with tweezers \\
\hline Gastroscope [13] & Banding device & Fell into another patient \\
\hline Gastroscope [14] & Brush tip & Pushed out of channel during reprocessing \\
\hline Colonoscope [15] & Clip & Fell into a patient two procedures later \\
\hline Duodenoscope [16] & Sponge & Observed during procedure, pushed out of channel after scope extraction \\
\hline
\end{tabular}

various models of endoscopes, as well as various defects that may be present. Therefore, both technicians and Al systems require extensive training and competency testing before they can successfully perform borescope examinations and interpret the findings.
That said, our main criticism of the Al program described by Barakat et al. is that its accuracy was assessed only by three gastroenterologists whose opinions were deemed the "gold standard." Ideally, defects identified by either endoscopists or Al systems should be validated by experts in endoscope design, reprocessing, and repair. The ongoing development of such pro- 
grams will undoubtedly require the collaboration of multidisciplinary teams including endoscope manufacturing experts, repair technicians, reprocessing personnel, infection preventionists, researchers, Al software developers, and clinicians. As the technology progresses, it is hoped that borescope examinations will become widely adopted as a proactive method for screening endoscopes to identify those in need of routine maintenance, repair, or refurbishment akin to colon cancer screening programs that identify patients with conditions that benefit from early identification and treatment.

\section{Competing interests}

Ofstead, Hopkins, and Eiland have received research grants, study materials, educational materials, or consulting contracts from $3 \mathrm{M}$ Company, Ambu, Auris Health, Advanced Sterilization Products, Boston Scientific Corporation, Laborie/Cogentix, Convergascent, Fortive, Healthmark, Cantel/Medivators, Pentax, and Steris. These companies were not involved in drafting this editorial.

\section{References}

[1] Ofstead CL, Quick MR, Wetzler HP et al. Effectiveness of reprocessing for flexible bronchoscopes and endobronchial ultrasound bronchoscopes. Chest 2018; 154: 1024-1034

[2] Ofstead CL, Heymann OL, Quick MR et al. Residual moisture and waterborne pathogens inside flexible endoscopes: Evidence from a multisite study of endoscope drying effectiveness. Am J Infect Control 2018; 46: 689-696

[3] Thaker AM, Kim S, Sedarat A et al. Inspection of endoscope instrument channels after reprocessing using a prototype borescope. Gastrointest Endosc 2018; 88: 612-619

[4] Barakat MT, Girotra M, Huang RJ et al. Scoping the scope: Endoscopic evaluation of endoscope working channels with a new high-resolution inspection endoscope (with video). Gastrointest Endosc 2018; 88: $601-611$
[5] Galdys AL, Marsh JW, Delgado E et al. Bronchoscope-associated clusters of multidrug-resistant Pseudomonas aeruginosa and carbapenem-resistant Klebsiella pneumoniae. Infect Control Hosp Epidemiol 2019; 40: 40-46

[6] Rauwers AW, Troelstra A, Fluit AC et al. Independent root cause analysis of contributing factors, including dismantling of 2 duodenoscopes, to an outbreak of multidrug-resistant Klebsiella pneumoniae. Gastrointest Endosc 2019; 90: 793-804

[7] Kumarage J, Khonyongwa K, Khan A et al. Transmission of MDR Pseudomonas aeruginosa between two flexible ureteroscopes and an outbreak of urinary tract infection: The fragility of endoscope decontamination. J Hosp Infect 2019; 102: 89-94

[8] Olympus Medical System Corp. Evis Exera III Bronchovideoscope 8031158. Silver Spring, MD: Food and Drug Administration; 2018: 2951238-2018-00665

[9] Olympus Medical Systems Corp. Evis Exera LLL Colonovideoscope 8493183. Silver Spring, MD: Food and Drug Administration; 2019: 2951238-2019-00711

[10] Olympus Medical Systems Corp. EVIS Lucera Elite Gastrointestinal Videoscope 7892908. Silver Spring, MD: Food and Drug Administration; 2018: 8010047-2018-01815

[11] Olympus Medical Systems Corp. EVIS Lucera Elite Colonovideoscope 8007877. Silver Spring, MD: Food and Drug Administration; 2018: 8010047-2018-02055

[12] Hoya Corporation Pentax Tokyo Office Pentax Video Duodenoscope 7399329. Silver Spring, MD: Food and Drug Administration; 2018: 9610877-2018-00068

[13] Olympus Medical Systems Corp. Evis Exera Gastroscope and Accessories, Flexible/Rigid 7475382. Silver Spring, MD: Food and Drug Administration; 2018: 7475382

[14] Olympus Medical Systems Corp. Evis Exera II Gastrointestinal Videoscope 10414005. Silver Spring, MD: Food and Drug Administration; 2020: 8010047-2020-05514

[15] Olympus Medical Systems Corp. Evis Exera III Colonovideoscope, 10619657. Silver Spring, MD: Food and Drug Administration; 2020: 8010047-2020-07147

[16] Olympus Medical Systems. Corp. Evis Exera II Duodenovideoscope, 10417002. Silver Spring, MD: Food and Drug Administration; 2020: 8010047-2020-05524 